\title{
Reinserção social de portadores de sofrimento psíquico: o olhar de usuários de um Centro de Atenção Psicossocial
}

| ' Fernanda Paranhos-Passos, ${ }^{2}$ Suely Aires |

Resumo: Com o objetivo de possibilitar o convívio social mais amplo dos portadores de sofrimento psíquico, a Reforma Psiquiátrica preconiza a ruptura do modelo de internação hospitalar e a consequente reinserção social desses sujeitos. Considerando que a reforma encontra-se em processo de construção, são necessárias pesquisas sobre a reinserção social visando contribuir para uma maior eficácia da rede de saúde mental. O presente artigo objetiva analisar a visão dos usuários de um serviço de saúde mental acerca da reinserção social dos portadores de sofrimento psíquico. O estudo contou com a participação de 20 usuários de um CAPS, que responderam a uma entrevista semiestruturada; os dados obtidos foram submetidos a uma análise discursiva. A análise aponta que o serviço é percebido como um local de acolhimento, seguro para os usuários; no entanto, os portadores de sofrimento psíquico ainda são vistos com preconceito por frequentarem um local de assistência psicológica. Além disso, os usuários do serviço não estão inseridos no mercado de trabalho. A partir do exposto, considerase que o serviço ainda não proporciona plenamente a reinserção social dos usuários. Fica clara a positiva mudança nos modos de tratamento da saúde mental, sendo o CAPS sinônimo de liberdade em seus diversos sentidos. Contudo, a reinserção ainda não atingiu outros espaços que não o próprio CAPS.

\author{
1 Estudante de Graduação \\ do curso de Psicologia da \\ Universidade Federal do \\ Recôncavo da Bahia. Membro \\ do Grupo de Pesquisa \\ Psicanálise, Subjetividade e \\ Cultura (CNPq). Bolsista do PET \\ Saúde Mental/ crack, álcool \\ e outras drogas (SMS/MS) \\ 2011/2012. Endereço eletrônico: \\ nanda_np@hotmail.com \\ 2 Professora Adjunta da \\ Universidade Federal do \\ Recôncavo da Bahia. Psicóloga. \\ Doutora em Filosofia da \\ Psicanálise (UNICAMP). \\ Coordenadora do Grupo \\ de Pesquisa Psicanálise, \\ Subjetividade e Cultura (CNPq). \\ Endereço eletrônico: suely. \\ aires7@gmail.com
}




\section{Introdução}

A partir das discussões dos modos de tratamento realizados nos hospitais psiquiátricos e a evidente objetificação dos sujeitos internados, a reforma psiquiátrica propõe um novo olhar sobre os portadores de sofrimento psíquico. Nesse contexto, visa reintegrá-los à sociedade, pois considera que a exclusão e o enclausuramento, por si sós, exacerbam a condição psíquica dos sujeitos. Desse modo, os serviços substitutivos aos hospitais psiquiátricos têm como objetivo a reinserção social dos portadores de sofrimento psíquico, devolvendo-lhes o convívio com seus pares, familiares e demais membros da sociedade, bem como a ocupação cidadã dos espaços sociais.

Sabendo da importância social da reinserção, faz-se necessário entendêla a partir do olhar dos usuários. Nesse sentido, o presente artigo tem como objetivo analisar a visão dos usuários de um serviço de saúde mental acerca de sua reinserção social, a partir dos serviços oferecidos no Centro de Atenção Psicossocial II Nova Vida, situado na cidade de Santo Antônio de Jesus, no estado da Bahia. Para tanto, é preciso delinear o histórico da saúde mental com a finalidade de problematizar a reinserção social e sua importância para toda a sociedade. Vale ressaltar que a reforma psiquiátrica ainda se apresenta em fase de construção, e que o entendimento desse processo é fundamental para propiciar práticas que promovam a reinserção.

De acordo com Foucault (2002), em toda sociedade, existem pelo menos quatro domínios das atividades humanas (trabalho, reprodução da sociedade, linguagem, atividades lúdicas), e sempre existem grupos de pessoas que não realizam certo tipo de atividade. No entanto, apenas o louco é excluído de todas essas esferas. Ao considerar os domínios indicados por Foucault, é importante destacar a categoria "trabalho", que, a partir das sociedades industrializadas, se tornou o primeiro elemento para determinar a loucura em um indivíduo. Se o louco não é economicamente ativo, é destinado à margem social, como indica Basaglia (2005a): o que a produção descarta está doente, o que está doente é separado.

Seguindo a lógica de excluir aqueles que não movimentavam a economia, desempregados, velhos, doentes e loucos foram alocados em grandes instituições. Toda essa classe marginalizada foi destituída de cidadania, afastada da família e do meio social. Esses locais eram destinados a esconder as mazelas sociais, sem fins terapêuticos e de reabilitação, até que no fim do século XVIII o médico 
psiquiatra Philippe Pinel categorizou a loucura como uma doença. A partir de

então, os médicos passaram a ser vigilantes, tutores internos e moderadores dos excessos a que a doença podia levar (BASAGLIA, 2005a), o que não modificou o status de marginalizado do louco. Pode-se considerar que a loucura foi transformada em "doença mental" com o advento do capitalismo, visto que o louco não tinha valor no mundo do trabalho: aquilo que não se encaixava na nova ordem social passou a ser visto como patológico, anormal, e, portanto, devia ser excluído e/ou corrigido, destinado a grandes instituições (FOUCAULT, 1975 apud CEDRAZ; DIMENSTEIN, 2005).

Goffman (2007) denomina Instituiçôes Totais aquelas em que os loucos foram internados. Suas características são: o controle das necessidades humanas pela organização burocrática, a vigilância intensa e a divisão entre o grupo dos internados e o grupo dos supervisores. Além disso, quando o sujeito é internado em instituições totais, inicia-se "uma série de rebaixamentos, degradações, humilhações e profanações do eu. O seu eu é sistematicamente [...] mortificado" (GOFFMAN, 2007, p. 24). Portanto, o sujeito deixa de ser um ator e passa a ser objeto de intervenções institucionais. A institucionalização visa objetificar os sujeitos e não perturbar a ordem e a regra da complexa organização (BASAGLIA, 2005a).

A mudança do olhar da Psiquiatria sobre o louco teve início na segunda metade do século XX, com o surgimento dos fármacos, pois estes permitiram aos pacientes um alívio dos sintomas, bem como certo nível de retorno à consciência. Desse modo, foi possível identificar que sintomas como apatia e embotamento não se referiam unicamente à doença, mas também à situação de internamento. Portanto, pode-se considerar que a ineficácia do hospital para tratamento não se dava apenas pela qualidade das terapias, e sim pela própria institucionalização.

A discussão sobre a ineficácia dos tratamentos psiquiátricos em regime de isolamento social permitiu que a Psiquiatria começasse a considerar que o caminho para o tratamento se dava com a modificação da estrutura asilar. Com tal intenção, surgiram diversos movimentos reformistas em Psiquiatria que afirmaram a necessidade de alteração da instituição manicomial com uma possível liberdade de circulação social dos portadores de sofrimento psíquico. ${ }^{1}$ No presente artigo, destacaremos o movimento protagonizado por Franco Basaglia na Itália, em função de sua influência na reforma psiquiátrica brasileira. 
Em 1968, Basaglia propôs a modificação dos modos de tratamento ofertados aos portadores de sofrimento psíquico, indicando a necessidade de abertura dos hospitais psiquiátricos com consequente tratamento em regime aberto. Uma reforma legislativa possibilitou que, por força de lei, a internação fosse voluntária, ou seja, aceita pelo sujeito, ou coercitiva apenas sob iniciativa e avaliação psiquiátrica. Em 1978, foi aprovada a Lei da Reforma Psiquiátrica, Lei n¹80, que proíbe a construção de novos hospitais psiquiátricos, passando para as administrações locais a responsabilidade de organizar novos serviços extrahospitalares. Essa lei ficou conhecida como Lei Basaglia.

A proposta de desinstitucionalização de Basaglia implica tanto o fechamento dos manicômios e a eliminação de coerções e tutelas quanto o questionamento do status de periculosidade do louco. Por conseguinte, o autor propõe um tratamento humanizado em serviços substitutivos que possibilitem o cuidado a partir de um espaço de interlocuções e produção de relações subjetivas. A desinstitucionalização, nesse contexto, tem o intuito de eliminar a medicalização e os meios de contenção como únicas formas de tratamento, permitir a relação do sujeito com o próprio corpo e "não usar o saber como técnica normativa, mas como possibilidade de criação de subjetividades" (TORRE; AMARANTE, 2001, p. 80). No entanto, cabe destacar que a mudança de um paradigma é realizada paulatinamente, principalmente quando se trata da cidadania de um público vulnerável que perdeu o direito de ser ativo diante da sociedade e de sua própria vida.

Acompanhando os movimentos reformistas em Psiquiatria, o Brasil iniciou a mudança no ano de 1978, juntamente com a reforma sanitária. Um grupo de trabalhadores em saúde mental formou o Movimento dos Trabalhadores em Saúde Mental (MTSM) no Rio de Janeiro, procurando entender e disseminar o papel social da Psiquiatria com o intuito de mudar o modelo clássico, até então vigente, e realizar mudanças na assistência. Diferentes parcelas da sociedade se envolveram nesse processo (TORRE; AMARANTE, 2001).

A luta brasileira teve continuidade com o projeto de lei Paulo Delgado, o qual declara a ineficiência dos tratamentos psiquiátricos e propõe a extinção progressiva dos hospitais psiquiátricos, impedindo a abertura de novos leitos ou o financiamento de outros além dos já existentes. Também propõe a criação de recursos assistenciais alternativos e estruturas não manicomiais, como unidades psiquiátricas em hospitais gerais, hospitais-dia, hospitais-noite, centros de convivência, entre outros (CEDRAZ; DIMENSTEIN, 2005). 
Todavia, o projeto foi rejeitado e substituído por uma lei que dispõe sobre a continuação da internação psiquiátrica como uma intervenção terapêutica válida, caso os recursos extra-hospitalares não sejam suficientes para o tratamento. Os hospitais psiquiátricos ainda se mantêm como um recurso possível no nosso país; porém, não podem mais ser classificados como a única forma de tratamento existente (CEDRAZ; DIMENSTEIN, 2005).

Em busca de consolidar um modelo de atenção à saúde mental aberto e de base comunitária, a Política Nacional de Saúde Mental no Brasil, pautada na lei no 10.216, de 2001, garante a livre circulação das pessoas com transtornos mentais pelos serviços, território e cidade, e oferece cuidados com base nos recursos que a comunidade apresenta. Esse modelo conta com uma rede de serviços e equipamentos variados, tais como os Centros de Atenção Psicossocial (CAPS), os Serviços Residenciais Terapêuticos (SRT), os Centros de Convivência e Cultura e os leitos de atenção integral (em Hospitais Gerais, nos CAPS III) (BRASIL, 2001). De acordo com dados levantados pelo Ministério da Saúde, até dezembro de 2010, o Brasil contava com 1.620 CAPS, 570 residências terapêuticas em funcionamento e 183 em implantação, além de 32.735 leitos psiquiátricos em hospitais gerais, distribuídos em todas as regiōes do país (BRASIL, 2010).

Uma das características mais marcantes dos serviços substitutivos ao hospital psiquiátrico diz respeito à variedade de terapêuticas que objetivam rumos distintos da Psiquiatria Clássica, do tratamento moral e do trabalho terapêutico (CEDRAZ; DIMENSTEIN, 2005). Em nossa apresentação, daremos ênfase a um serviço substitutivo específico, o Centro de Atenção Psicossocial (CAPS), por se tratar do local onde realizamos nossa pesquisa. De acordo com o Ministério da Saúde (BRASIL, 2004), tal serviço tem como objetivo oferecer atendimento à população de sua área de abrangência, realizando, dentre outras atividades, o acompanhamento clínico e a reinserção social por meio de oficinas terapêuticas, tratamento medicamentoso, atendimento em grupo ou individual às famílias, atendimento psicoterápico, visitas domiciliares e atividades comunitárias.

Ao realizar uma busca em artigos científicos referentes à Reforma Psiquiátrica, é possível perceber dois conceitos principais nesse campo: reabilitação psicossocial e reinserção social. Todavia, eles são utilizados de forma imprecisa e diversificada, ou como termos sinônimos, por diversos autores. A despeito da imprecisão conceitual, tais noções são de extrema relevância para a reforma psiquiátrica, como atestam diferentes artigos. 
De acordo com Dimenstein e Bezerra (2009), a reforma propõe a substituição do tratamento baseado no isolamento por alternativas que valorizam o convívio familiar e comunitário, tendo como principal estratégia a reabilitação psicossocial. Tal afirmação está em concordância com os objetivos dos serviços substitutivos apresentados no Manual do CAPS (BRASIL, 2004), os quais visam à reinserção social de seus usuários por meio do acesso ao trabalho, lazer, exercício dos direitos civis e fortalecimento dos laços familiares e comunitários.

Objetivando maior suporte teórico, foi realizada uma pesquisa bibliográfica em sites especializados, o Scientific Electronic Library Online (SciELO) e Periódicos Eletrônicos em Psicologia (PEPsic), utilizando-se as palavras-chave reabilitação psicossocial e reinserção social. Foram encontrados mais de 20 artigos que discutem a temática; porém, a maioria apenas cita os termos como conceitos importantes e imprescindíveis ao contexto da reforma, não discorrendo sobre suas definições. De modo geral, apresentam a reabilitação psicossocial como um operador teórico-prático da reforma psiquiátrica, orientador dos serviços substitutivos, e cujo processo seria de facilitar ao indivíduo com limitaçóes a restauração, no melhor nível possível de autonomia, atingindo seu nível potencial de funcionamento independente na comunidade. Pitta (1996, apud PINTO; FERREIRA, 2010) alerta para o reducionismo que esse conceito pode apresentar, tendo em vista que a palavra "reabilitação" pode soar como um retorno à normalidade perdida, o que manteria um diferencial de poder, assegurando a minorização da loucura. Já a reinserção social é vista como o principal objetivo da reabilitação psicossocial, referindo-se ao convívio do sujeito nas instâncias sociais, possibilitando o processo de trocas.

Desse modo, o presente trabalho considera tais conceitos de acordo com a definição apresentada a seguir: a reabilitação psicossocial é uma estratégia que visa proporcionar a autonomia do portador de sofrimento psíquico para que ele possa atuar com independência nos diversos contextos sociais, exercendo sua cidadania plena, e direcionando-o à reinserção social. Esta, por sua vez, se refere à possibilidade de convívio do portador com seus familiares, pares, amigos e demais membros da sociedade, através da circulação e ocupação dos espaços sociais.

Deve-se discutir a reinserção tendo em vista o histórico social de exclusão da loucura. A sociedade ocidental se organizou de modo a excluir o que é diferente e, portanto, marginalizou o portador de sofrimento psíquico, criando rótulos 
e estigmas pejorativos, além da destituição de seus direitos civis. A reforma

psiquiátrica tem como proposta devolver tal público aos espaços sociais, através de açóes que permitam que essas pessoas se tornem autônomas e sujeitos de suas ações.

Diante disso, não basta somente reinserir: é preciso que haja antes uma reabilitação, ou seja, oferecer ao usuário de saúde mental possibilidades que o capacitem para a vida em sociedade, considerando as diversas perdas sofridas pelo sujeito em decorrência do seu adoecimento. Do mesmo modo, não basta só reabilitá-lo sem proporcionar a ocupação cidadã por parte do louco de seu lugar na sociedade. Nesse sentido, esses dois conceitos devem andar juntos para que sejam realizadas ações profícuas no âmbito da saúde mental.

Considerando que a Reforma Psiquiátrica ainda é recente e se encontra em processo de construção, faz-se necessário problematizar a reinserção social a partir do olhar dos usuários, os principais sujeitos do processo, com vistas a contribuir para uma maior eficácia da rede de saúde mental.

\section{Método}

Esta pesquisa exploratória qualitativa foi realizada através de um estudo de campo no Centro de Atenção Psicossocial Nova Vida, localizado no município de Santo Antônio de Jesus, Bahia. Trata-se de um CAPS II (BRASIL, 2002), que funciona de segunda a sexta-feira, das $8 \mathrm{~h}$ às $17 \mathrm{~h}$. Conta em seu corpo com profissionais da área de Psiquiatria, Psicologia, Enfermagem (cursos superior e técnico), Farmácia, Fisioterapia, Serviço Social, monitores de oficinas, além de recepcionistas, porteiro e voluntários, e atende a um público de aproximadamente 40 pessoas por dia.

O presente estudo contou com a participação voluntária de vinte usuários do serviço. Foram entrevistados os vinte primeiros usuários que tiveram disponibilidade de responder à entrevista. A coleta de dados foi efetuada através de entrevista semiestruturada de forma individual e presencial, em agosto e setembro de 2011. Para maior fidedignidade da análise dos dados, as entrevistas foram gravadas. Os dados coletados foram organizados em categorias temáticas de acordo com a semelhança de respostas de cada grupo; em seguida, foram submetidos a uma análise discursiva, de modo a considerar a relação entre significantes/termos utilizados e significados sociais e particulares. Consideramos a análise do discurso um procedimento viável para a pesquisa, 
pois se preocupa com a linguagem e com o seu papel na constituição da vida social e psicológica, entendendo que o discurso pode ser definido como conjunto de afirmações que constrói objetos e uma gama de posições para o sujeito falante (NOGUEIRA, 2008).

Todos os participantes foram previamente esclarecidos sobre a pesquisa e seus objetivos e assinaram o Termo de Consentimento Livre e Esclarecido, conforme a Resolução no 196, de 10 de Outubro de 1996, que trata da ética nas pesquisas envolvendo seres humanos. O projeto foi encaminhado ao Comitê de Ética da Faculdade Maria Milza na cidade de Cruz das Almas, Bahia, recebendo parecer favorável, de acordo com o protocolo $n^{\circ}$ 145/2010. As informaçôes foram tratadas de forma sigilosa e anônima, respeitando a privacidade dos sujeitos envolvidos.

\section{Resultados e discussão}

A partir das falas dos entrevistados foi possível organizar três categorias temáticas: Modos de Tratamento do Sujeito (dividida em duas subcategorias, Hospital Psiquiátrico e Centro de Atenção Psicossocial II Nova Vida); Preconceito/ Discriminação (contendo as subcategorias Antes do CAPS e Após o início do tratamento no CAPS); e, por último, a categoria Relacionamento/Convivência, com as subcategorias Família, CAPS e Trabalho.

\section{Modos de Tratamento do Sujeito}

Dos vinte usuários entrevistados, 12 declararam que já foram internados em hospitais psiquiátricos, e, quando perguntados sobre os modos de tratamento, a maioria apresentou queixas com relação à violência sofrida nesse espaço, à medicalização abundante e ao isolamento como um fator de extremo sofrimento.

Resgatando a história dos hospitais psiquiátricos, trata-se de um espaço de tratamento dos alienados, aqueles que estão fora da realidade e que têm alterada sua possibilidade de juízo. Sendo a alienação um distúrbio das paixões, nessa concepção, o louco deve receber um tratamento moral e disciplinado no interior do hospício para tornar-se um sujeito de direito (TORRE; AMARANTE, 2001). Além disso, por ter seu juízo desajustado, considera-se o alienado como perigoso para si e para os demais: "Todo alienado constitui, de algum modo, um perigo para seus circunstantes, porém, em especial, para si próprio" (KRAEPELIN, 1988 apud TORRE; AMARANTE, 2001). 
Para tal pensamento, delineado por Pinel, o isolamento no manicômio é uma

forma eficaz de tratamento, pois a instituição é organizada de forma a afastar as influências maléficas e morbígenas que causam e agravam a alienação, sendo a instituição um instrumento de cura (TORRE; AMARANTE, 2001). Porém, esse isolamento agride de maneira profunda o sujeito e o "faz desligar, de forma explicitamente violenta, os diferentes laços de construção e pertencimento humanos" (RODRIGUES; CUNHA, 2007, p. 343). O sujeito é obrigado a viver num lugar estranho, cheio de restriçóes, degradando sua identidade e apartado de seus laços familiares, como podemos perceber na fala de uma usuária:

A gente ficava lá presa; quando eu cheguei, logo ficava amarrada, aí ficava presa lá; a família não podia ir lá ver. Eu só vi minha mãe quando vim embora. [...] Tinha um enfermeiro lá que era bonzinho, conversava comigo, não era ruim não. Mandava se acalmar pra sair de lá porque lá era um inferno. (Sujeito 12)

Além do isolamento, que já é uma agressão ao sujeito, a violência física propriamente dita e as medicalizações são algo recorrente nos modos de tratamento dos hospitais psiquiátricos, onde os usuários são submetidos "a terapias violentas e desumanas, como administração de medicamentos em dosagens elevadas, camisas de força, eletrochoque, entre outras" (JORGE; BEZERRA, 2004, p. 552). De acordo com Sidrin (2010), a violência praticada nos hospitais é consequência da assistência ineficaz; na condição de crônicos, os pacientes se tornam alvo fácil de violência, e nenhum deles reclamará, pois todos perderam seu status de cidadão.

Horrível, fui acorrentada, apanhei muito, fui maltratada. É... fiquei muito tempo sem tomar banho, não dava comida à gente, dava remédio direto. Também na época que eu fui internada eu tava muito violenta, quando eu me soltava eles espancava muito a gente, pegava muita coisa, o castigo era esse: deixava a gente amarrada, tomava muita injeção, aí tome injeção, tome injeção, aí pronto [...]. No hospital X, é o pior que tem, pra mim é o pior, eu ainda tenho as marcas da corrente. (...) No hospital Y sofri um pouquinho, porque lá um paciente agredia o outro, mas o hospital X pra mim foi o pior, um pesadelo. (Sujeito 14)

Quase que me mata lá. E o que foi que fizeram? Me deram remédio de doido lá. Remédio pra matar mesmo, injeção braba. Não podia andar, se quisesse andar tinha que arrastar a bunda no chão. (Sujeito 9)

De acordo com Rodrigues e Cunha (2007), o manicômio é a tradução mais completa de exclusão, controle e violência, em que os muros escondem a violência (física e simbólica), retiram a culpa da sociedade e descontextualizam os processos sócio-históricos da produção e reprodução da loucura. 
Quando perguntados sobre os serviços do CAPS II Nova Vida, os usuários demonstraram uma grande satisfação, valorizando a liberdade - em contraposição ao hospital como instituição fechada - e a autonomia em escolher fazer ou não alguma atividade. Também enfatizaram o carinho e o respeito dos profissionais, que, em algumas situações, se mostram mais carinhosos do que a própria família.

É bom. Me tratam melhor que o povo de dentro de casa. É mais carinho, conversa com a gente; em casa não, fica chamando a gente de doida. (Sujeito 13)

Aqui no CAPS é melhor, porque a gente entra oito horas da manhã, faz física, faz artesanato, tem aula de música, tem jogo de bola, tem física com os médicos; a gente sai quatro horas da tarde e fica livre pra a gente sair pra onde quiser. (Sujeito 6)

São carinhosos com a gente, não obriga a gente a fazer as atividades, a gente faz quando quer, a gente estuda, brinca, faz oficina, tem a ginástica, a caminhada, é ótimo, ótimo. [...] Tratam a gente muito bem, não tenho nada o que dizer deles, o pessoal da cozinha, os médicos melhor ainda. (Sujeito 18)

É importante considerar que este estudo aconteceu no espaço do CAPS, sendo entrevistados os primeiros usuários que tiveram interesse em participar da pesquisa. Tal procedimento pode ter produzido respostas específicas, com maior valorização do cuidado ofertado pelo CAPS, por se tratar de enunciados formulados por um público que aderiu ao modelo da reforma psiquiátrica e que, por conseguinte, pode ter respondido em conformidade às expectativas dos profissionais do serviço e da entrevistadora. No entanto, tal limitação do estudo não compromete os objetivos da pesquisa, uma vez que outros elementos foram investigados para além da vivência no serviço, como, por exemplo, as relações dos usuários com familiares e a realização de atividade remunerada.

\section{Preconceito/ Discriminação}

Um importante tema que emergiu nas falas dos entrevistados se refere ao preconceito que o usuário de um serviço de saúde mental sofre. $\mathrm{O}$ preconceito e a ligação entre loucura e violência advêm da idade média, quando a loucura era percebida como uma possessão diabólica (CIRILO; FILHO, 2008). Tal preconceito foi aprofundado com a exclusão dos portadores de sofrimento psíquico do meio social, fazendo com que fossem esquecidos e, por conseguinte, temidos pela sociedade.

[...] desde 15 anos que eu tenho problema de saúde. Depois que meu marido meteu uma barra de ferro na cabeça e eu fiquei no HGE 6 meses e levei 48 pontos, eles começaram a me discriminar [...]. (Sujeito 18) 
[...] antes ficavam com medo de mim, de eu quebrar as coisas, de ficar nervoso, não

atender, sair do sério, sair caminhando sem destino, sem saber para onde ia, não tinha hora pra voltar. (Sujeito 6)

É importante destacar que tal preconceito e discriminação ocorrem antes do usuário frequentar o CAPS Nova Vida e também após. De acordo com Mello e Fuguerato (2008):

Não basta modificar os locais de atendimento se não forem modificadas as representações associadas à doença mental, fazendo um movimento que dissocie a loucura da violência, da improdutividade e da incapacidade de articulação social (p.458).

Mesmo com o objetivo de interação entre os usuários e a sociedade, esta ainda percebe o portador de sofrimento psíquico como alguém desacreditado, sujeito da desrazão. Nesse sentido, as mudanças no contexto da saúde mental não devem ocorrer somente nos modos de tratamentos das instituições, mas com toda a comunidade, implicando as pessoas nesse processo de acreditar nas potencialidades dos sujeitos.

Rapaz, sempre muda, viu, pra algumas pessoas que... ignorante, entendeu? Mas, pra outras, é normal. [...] Agora uns ignorante, é "do CAPS é doido", essas coisas, mas não me abala nada, tá ligado? Eu nem ligo mais. (Sujeito 1, em resposta à pergunta "O convívio mudou depois que você passou a frequentar o CAPS?”)

[...] mas, uma vez que nós caminhou aí, nós foi caminhar, teve um velho que tava trabalhando e chamou a gente de doido, mas nós não somos doido. Nós somos uma pessoa que é capaz de tudo, de sobreviver, caminhar alegre, sorrir. O importante é isso, que nós somos feliz. (Sujeito 4)

A gente daqui do CAPS ficam dizendo que a gente é maluco; um vizinho lá me chama de maluca e fala alto. Minha sobrinha mais velha de 10 anos me chama de maluca e fica me irritando. [...] Só em saber que a pessoa é daqui do CAPS a pessoa é maluca; que antes do CAPS é normal e depois daqui diz que é maluco, só porque aqui tem tratamento psicológico. (Sujeito 12)

Através das falas, é possível perceber que o fato dos sujeitos frequentarem o CAPS é uma prova da insanidade mental, o que gera preconceito. Para alguns entrevistados, antes de frequentar um serviço de saúde mental, o convívio com familiares e pessoas próximas era considerado normal; porém, a confirmação do sofrimento psíquico foi um elemento para a mudança de comportamento perante tais sujeitos.

[...] A diferença é porque eles me tratavam igual, hoje em dia é: "cadê seus malucos, vai pro CAPS hoje, vai ver teus doido hoje?” (Sujeito 14) 
Ah, eles maltratam muito a gente, assim, verbalmente. [Entrevistador: Eles quem?] O pessoal da rua, o pessoal da família, porque acha que a gente é louco, porque aqui no CAPS é louco, todo mundo que tá aqui dentro é louco. Então é uma discriminação horrível que têm com a gente. (Sujeito 15)

\section{Relacionamento/Convivência}

Um dos principais objetivos do dispositivo de saúde mental CAPS se refere à reinserção social dos usuários. Isso significa que um dia houve exclusão social e faz-se necessário devolver o usuário ao seio social, através do convívio com seus familiares, pares, amigos e demais membros da sociedade, por meio da circulação e ocupação dos espaços sociais. Para tanto, esse serviço lança mão de várias estratégias para aproximar o usuário da sociedade e também das famílias, pois muitas vezes o usuário é desacreditado e encarado como alguém que finge ter o sofrimento psíquico para obter benefícios; além disso, muitas famílias criam uma distância dos usuários por preconceito ou vergonha, como pode ser observado na fala dos usuários:

Eu vou na casa da minha família mais pra ver minha mãe, tá ligado? Meu convívio com minha família é bom, é bom assim em meus termos de eu falar, de conversar, mas eu prefiro ficar mais distante, porque nas horas que eu precisava, elas não me ajudaram. "Ah, esse aqui é descaração". [Entrevistador: E você acha que o convívio é importante para o seu tratamento?] Hoje não é mais não, porque eu tenho 5 anos de CAPS, e eu mesmo faço minha consulta, eu mesmo pego meu remédio, pra quê? Enfrento essa dificuldade, sabe? Sozinho. Ninguém vem aqui; tem uma festa ninguém vem, eu nem chamo mais, pra quê? Como tô dizendo pra senhora, minha família é primeiramente Deus, minha esposa, e o CAPS que cuida de mim, mas minha mãe é mãe, né? Eu dou um abraço nela, mas não pra ficar lá; converso com ela e venho embora logo. Mas é muito difícil, minha família é muito difícil. Não entendem. (Sujeito 1)

Minha família não me acompanha assim, sabe?! Minha família, assim, no sanatório, me botaram no sanatório, mas nunca me visitaram, nenhum dos dois, porque até hoje tem vergonha, tem preconceito de eu tá aqui. Mas eu não parei meu tratamento por causa... não liguei por causa disso, porque quem precisa de ser tratada sou eu, não são eles. (Sujeito 14)

Minha família eu não tenho contato, só uma que anda comigo para o INSS, pra qualquer lugar ela vai comigo, mas o resto me despreza, diz que eu sou louca, que eu sou do CAPS, essas coisas assim. (Sujeito 15)

Apesar da falta de apoio das famílias expressa na fala dos entrevistados, os usuários encontram no CAPS um novo lar. 
Aqui é meu segundo lar. Quando eu saí do sanatório eu vim direto para aqui. Aqui, eu tive aqui amor, carinho, respeito, deveres, direitos, mas também... é... nem tudo a gente pode fazer aqui, tenho minhas limitação, respeito todo mundo, trato todo mundo com respeito, também me trata com amor, com carinho, quando eu tou em crise me abraça, tem toda paciência comigo, eu tenho assistência dos meus médicos aqui. Então o CAPS pra mim, aqui é meu segundo lar. (Sujeito 14)

Aqui é diferente, é totalmente diferente; aqui é o segundo lar que a gente tem, que eu tenho, eu particularmente tenho um segundo lar meu. (Sujeito 15)

Como aponta Rietra (1999 apud MARZANO; SOUZA, 2004), os CAPS representam mais do que uma alternativa ao modelo hospitalar: eles tornam possível o desenvolvimento de laços sociais e interpessoais, indispensáveis para o estabelecimento de novas possibilidades de vida. Além disso, segundo Marzano e Souza (2004), o indivíduo depende de um lugar de referência e um lugar onde ele possa formar vínculos, como o CAPS, o que possibilita sua reintegração social. As falas dos usuários entrevistados do CAPS II Nova Vida corroboram esta ideia, pois eles enxergam o CAPS como sua casa, um lugar em que encontram uma rede de apoio social representada não só pelos profissionais, mas também, e principalmente, por outros usuários, como uma família.

Minha família é aqui no CAPS, porque os outros... (Sujeito 17)

Meus amigos daqui do CAPS pra mim é uma família, todos me chamam de mãe e eu me sinto feliz, me sinto bem. Quando chega sexta-feira, que já não tem CAPS, aí eu só fico em casa já triste, aí sábado é pior, domingo é o pior dia pra mim. Eu fico pedindo a Deus que chegue segunda para eu retornar novamente. [...] Então com a minha família, é como se eu não tivesse, a minha família é o CAPS. [...] a gente desabafa e é muito bom. A gente sente a sensação de alguém que lhe compreende, lhe entende e lhe aceita como você é. (Sujeito 19)

Quando a gente tá em crise um vai dá uma palavra de conforto, dá um apoio, outro dá um apoio, outro fica com você ali na cama, na maca até a pessoa melhorar. É muito bom mesmo o tratamento daqui. (Sujeito 15)

Quando falamos de reinserção social de portadores de sofrimento psíquico, devemos atentar ao elemento "trabalho". Para tal, é necessário se reportar à história dos manicômios, onde as pessoas internadas eram aquelas não produtivas economicamente (FOUCAULT, 2002), incluindo os portadores de sofrimento psíquico. 
De acordo com a Portaria no 3.088 de 23 de dezembro de 2011 (BRASIL, 2011), que institui sobre a Rede de Atenção Psicossocial no âmbito do Sistema Único de Saúde, esta deve promover, dentre outros aspectos, a reabilitação e a reinserção das pessoas com transtorno mental e com necessidades decorrentes do uso de crack, álcool e outras drogas, por meio do acesso a trabalho, renda e moradia solidária. Segundo o documento, a reabilitação psicossocial é composta por iniciativas de geração de trabalho e renda, empreendimentos solidários ou cooperativas sociais. Nesse sentido, uma das marcas da reinserção se refere à ocupação do público em sofrimento psíquico em atividades laborais produtivas, promovendo assim um novo olhar social sobre os usuários da rede de saúde mental. Ao serem perguntados sobre o exercício de atividade remunerada, apenas três usuários declararam trabalhar.

Eu trabalho na Kombi, ele dirige e eu trabalho na Kombi. (Sujeito 5)

Às vezes, faço biscate, pintura de carro. (Sujeito 6)

Trabalho de ajudante de pedreiro, quando eu tô fora daqui do CAPS. (Sujeito 7)

Como podemos perceber nas falas, o trabalho exercido pelos usuários é em forma de biscate (sic) e como uma ajuda aos colegas, ou seja, um trabalho informal. Segundo Goulart e Guimarães (2002, apud SIDRIN, 2010), o valor atribuído ao trabalho tem raízes históricas na consolidação do capitalismo no século XX. Sendo o trabalho a atividade social mais valorizada, desemprego e informalidade contribuem para a exclusão social (CAMPOS et al. 2003, apud SIDRIN, 2010).

Os outros entrevistados declararam ser aposentados e/ou beneficiários da Seguridade Social. Tal benefício ocorre após o laudo dos profissionais do CAPS, confirmando a não adaptabilidade do usuário ao trabalho, justificada por sua condição psíquica. Como aponta Sidrin (2010), favorecer benefícios da Seguridade Social para os usuários é uma maneira de devolver-lhes condição financeira mínima, imprescindível para uma vida digna. Ainda de acordo com a autora, apesar dos benefícios, a aposentadoria dos usuários leva a uma legitimação da incapacidade, o que deve estar sempre em avaliação para não ser uma prática assistencialista.

De modo geral, o trabalho ainda é um elemento incipiente na realidade dos usuários entrevistados. Apesar da não valorização social do trabalho informal, no entanto, "o importante é resgatar a funcionalidade do paciente, e, na melhor das hipóteses, ajudá-lo a conquistar formas de subsistência” (SIDRIN, 2010, p. 111). 
Considerando a reinserção social como possibilidade de convívio do portador

de sofrimento psíquico com seus familiares, pares, amigos e demais membros da sociedade através da circulação e ocupação dos espaços sociais, o estudo aponta que os usuários entrevistados não estão plenamente reinseridos na sociedade, pois o CAPS é o único local de socialização desses sujeitos e ainda existe um grande preconceito direcionado a esse público por frequentar um local de assistência psicológico-psiquiátrica. Além disso, de forma geral, os usuários do serviço não estão inseridos no mercado de trabalho, o que conta como mais um ponto de invisibilidade social.

\section{Considerações finais}

A mudança de paradigma da saúde mental não diz respeito somente ao lugar onde é realizado o tratamento ou ao modo de cuidado; o sofrimento psíquico vai muito além da classificação dos sintomas em categorias. Para compreendêlo, é preciso pôr entre parênteses a doença e o modo como ela foi classificada para considerar o doente no desdobramento de modalidades humanas. Enquanto profissionais, devemos ter um conhecimento técnico dos transtornos mentais, porém sempre aliado aos direitos humanos, pois, independente da patologia, existe ali um sujeito que sofre.

O CAPS, como serviço substitutivo, tem a tarefa de acreditar no desacreditado e imprimir no dia a dia do serviço formas de reabilitar os sujeitos, de maneira a resgatar a autonomia, a subjetividade e a autoconfiança de um público que historicamente foi excluído de todos os ambientes e destituído de seus papéis sociais.

A partir do exposto, podemos afirmar que ainda não ocorre uma efetiva reinserção social dos usuários. Fica clara a positiva mudança nos modos de tratamento da saúde mental, sendo o CAPS sinônimo de liberdade em seus diversos sentidos e de humanização, porém a reinserção ainda não atingiu outros espaços que não o próprio CAPS. Os usuários ainda não se encontram no seio de suas famílias, sendo vítimas de preconceitos; nas ruas, são discriminados e estigmatizados como "loucos do CAPS", e no que se refere à atividade produtiva, de modo geral, são excluídos desse rol, o que impede sua maior visibilidade.

Levando em consideração a definição de reinserção social proposta pelo presente artigo, o convívio social do usuário se restringe aos espaços do CAPS, serviço que representa para os usuários uma família e um local onde se encontram 
os amigos. De fato, é compreensível que o CAPS se torne um ambiente acolhedor que concentra parte dos outros espaços externos, uma vez que dentro do serviço o usuário encontra carinho, respeito e pessoas que se interessam por suas histórias e habilidades, ao contrário do espaço externo ao serviço, onde usualmente existe preconceito, desrespeito e exclusão.

Analisando esse contexto, pode-se afirmar que as mudanças de paradigma na saúde mental não devem ocorrer somente dentro dos serviços, mas também fora deles. A exclusão e o estigma do portador de sofrimento psíquico estão arraigados na sociedade. É preciso, portanto, planejar ações no sentido de desmistificar a loucura, aproximando os ditos normais dos loucos, mostrando que dentro dos serviços de saúde mental existe vida, sujeitos e potencialidades. Ou seja, a prática de reabilitação também deve ser realizada com os não loucos, uma vez que eles foram desabilitados a acreditar na loucura. Desse modo, teremos então uma reabilitação inversa direcionada a toda a sociedade, no sentido de acreditar na autonomia e na atuação independente do portador de sofrimento psíquico. Somente quando a sociedade conhecer a história da loucura e dos manicômios poderá haver uma aceitação desse público, e então poderemos falar de uma reinserção social. ${ }^{2}$

\section{Referências}

AMARANTE, P. Locos por la Vida: la trayectoria de la reforma psiquiátrica en Brasil. Buenos Aires: Asoc. Madres de Plaza de Mayo, 2006.

AMARANTE, P. Sobre duas proposições relacionadas à Clínica e à Reforma Psiquiátrica. In: Psicanálise e Psiquiatria: controvérsias e convergências. Rio de Janeiro: Rios Ambiciosos, 2001, p. 103-110.

BARROS, M.M.M. ; JORGE, M.S.B.; PINTO, A.G.A. Prática de saúde mental na rede de atenção psicossocial: a produção do cuidado e as tecnologias das relações no discurso do sujeito coletivo. Rev. APS, Juiz de Fora, v. 13, n. 1, p. 72-83 2010. Disponível em: <http:// www.aps.ufjf.br/index.php/aps/article/viewFile/515/299>. Acesso em: $26 \mathrm{dez} .2011$.

BASAGLIA, F. A destruição do Hospital Psiquiátrico como lugar de Institucionalização. In:__-___. Escritos selecionados em saúde mental e reforma psiquiátrica. Rio de Janeiro: Garamond, 2005, p. 23-34.

BASAGLIA, F. Corpo e Instituição. In: - Escritos selecionados em saúde mental e reforma psiquiátrica. Rio de Janeiro: Garamond, 2005, p. 23-34. 
BIRMAN, J.; COSTA, J.F. Organização de instituições para uma Psiquiatria comunitária.

In: AMARANTE, P. (Org.). Psiquiatria Social e Reforma Psiquiátrica. Rio de Janeiro: Fiocruz, 1994, p. 41-72.

BRASIL. Ministério da Saúde. Política Nacional de Saúde Mental. Brasilia, 2001. Disponível em: <http://www.cress-pa.org.br/files/u4/11_Pol_SaudeMental.pdf>. Acesso em: 05 jul. 2011.

BRASIL. Ministério da Saúde. Portaria no 3.088, de 23 de dezembro de 2011. Institui a Rede de Atenção Psicossocial para pessoas com sofrimento ou transtorno mental e com necessidades decorrentes do uso de crack, álcool e outras drogas, no âmbito do Sistema Único de Saúde. Diário Oficial da República Federativa do Brasil, Brasília-DF, no 247, Seção 1, p. 230, 2011.

BRASIL. Ministério da Saúde Secretaria de Atenção. Departamento de Ações programáticas Estratégicas. Saúde Mental no SUS: os Centros de Atenção Psicossocial. Brasília-DF, 2004. Disponível em: <http://www.ccs.saude.gov.br/saude_mental/pdf/SM_Sus.pdf>. Acesso em: 15 mar. 2011.

BRASIL. Ministério da Saúde. Saúde Mental - Dados em Saúde Mental. Portal da Saúde. Brasília-DF, 2010. Disponível em: <http://portal.saude.gov.br>. Acesso em: 05 jul. 2011.

CEDRAZ, A.; DIMENSTEIN, M. Oficinas terapêuticas no cenário da Reforma Psiquiátrica: modalidades desinstitucionalizantes ou não? Rev. Mal-Estar Subj. [online]. Fortaleza, v. 5, n. 2, p. 300-327, 2005. Disponível em: <http://redalyc.uaemex.mx/src/ inicio/ArtPdfRed.jsp?iCve=27117013006>. Acesso em: 17 dez. 2010.

CIRILO, L.S.; FILHO, P. de O. Discursos de Usuários de um Centro de Atenção Psicossocial - CAPS e de seus Familiares. Psicologia Ciência e Profissão, Campina Grande, v. 28 n. 2, p. 316-329, 2008. Disponível em: <http://pepsic.bvsalud.org/pdf/pcp/v28n2/ v28n2a08.pdf>. Acesso em: 26 dez. 2011.

DIMENSTEIN, M.; BEZERRA, C.G. Alta-Assistida de usuários de um hospital psiquiátrico: uma proposta em análise. Pysis: Revista de Saúde Coletiva, Rio de Janeiro, v. 19 n. 3, p. 829-848, 2009. Disponível em: <http://www.scielo.br/pdf/physis/v19n3/a16v19n3. pdf>. Acesso em: 18 dez. 2010.

FOUCAULT, M. A Loucura e a Sociedade. In. Problematização do Sujeito: psicologia, Psiquiatria e psicanálise. Rio de Janeiro: Forense Universitária, 2002, p. 259-267.

GOFFMAN, E. Manicômios, prisóes e conventos. São Paulo: Perspectiva, 2007, p. 15-69.

JORGE, M.S.B.; BEZERRA, M.L.M.R. Inclusão e exclusão social do doente mental no trabalho: representações sociais. Texto Contexto Enferm. Florianópolis, 13, n. 4, p. 551-558, 2004. Disponível em: <http://redalyc.uaemex.mx/pdf/714/71413407.pdf>. Acesso em: 23 nov. 2011. 
MARZANO, M.L.R.; SOUSA, C.A.C. de. O espaço social do CAPS como possibilitador de mudanças na vida do usuário. Texto Contexto Enferm. Florianópolis v. 13 n. 4, p. 577584, 2004. Disponível em: <http://redalyc.uaemex.mx/pdf/714/71413410.pdf>. Acesso em: 26 dez. 2011.

MELLO, R.; FUGUERATO, A.R.F. Representaçōes de usuários, familiares e profissionais acerca de um centro de atenção psicossocial. Esc Anna Nery Rev Enferm. Rio de Janeiro, v. 12, n. 3, p. 457-464, 2008. Disponível em: <http://www.scielo.br/pdf/ean/v13n3/v13n3a04. pdf>. Acesso em: 26 dez. 2011.

NOGUEIRA, C. Análise do discurso: diferentes concepçōes na prática de pesquisa em psicologia social. Psic.: Teoria e Pesquisa. Brasília, v. 24, n. 2, p. 235-242, 2008. Disponível em: <http://www.scielo.br/pdf/ptp/v24n2/13.pdf>. Acesso em: 20 maio 2010.

PINTO, A.T.M.; FERREIRA, A.R.L. Problematizando a reforma psiquiátrica brasileira: a genealogia da reabilitação psicossocial. Psicologia em Estudo. Maringá, v. 15, n. 1, p. 27-34, 2010. Disponível em: <http://www.scielo.br/pdf/pe/v15n1/a04v15n1.pdf>. Acesso em: 18 dez. 2010.

RODRIGUES, J.; CUNHA, G. Movimento Nacional da Luta Antimanicomial. In: SEMINÁRIO NACIONAL MOVIMENTOS SOCIAIS, PARTICIPAÇÃO E DEMOCRACIA. 2., 2007, Florianópolis, Anais... Florianópolis: UFSC, 2007. p. 341-351. Disponível em: <http://www.sociologia.ufsc.br/npms/paula_v_grunpeter.pdf $>$. Acesso em: 20 maio 2010.

TORRE, E.H.; AMARANTE, P. Protagonismo e subjetividade: a construção coletiva no campo da saúde mental. Ciênc. Saúde coletiva [online]. Rio de Janeiro, v. 6, n. 1, p. 73-85, 2001. Disponível em: <http://redalyc.uaemex.mx/pdf/630/63060106.pdf>. Acesso em: 22 maio 2010.

\section{Notas}

${ }^{1}$ São considerados movimentos reformistas em Psiquiatria: a psicoterapia institucional, as comunidades terapêuticas, a Psiquiatria de Setor, a Psiquiatria Preventiva, a Antipsiquiatria e a Psiquiatria Democrática. Para maiores detalhes, conferir os trabalhos de Birman e Costa (1994) e Amarante (2006). ${ }^{2}$ F.P.Passos contribuiu neste artigo com a elaboração do texto, coleta e análise de dados e revisão bibliográfica. S. Aires contribuiu com a análise de dados e revisão crítica do texto. 
Social rehabilitation of patients with psychological distress: the gaze of users of a Psychosocial Care Center

With the objective of enabling the broader social life of people with mental disorder, the Psychiatric Reform advocates to disrupt the hospitalization model and subsequent reintegration of these individuals. Whereas the reform is in process of construction, research is needed on the social reintegration to contribute to greater effectiveness of mental health network. This paper aims to analyze the views of users of a mental health service about the social rehabilitation of patients with psychological distress. The study involved the participation of 20 users of a CAPS, who responded to a semistructured interview, data were subjected to discourse analysis. The analysis indicates that the service is perceived as a place of welcome, safe for users, however, patients with psychological distress are still viewed with prejudice by attending a place of psychological assistance. Additionally, users of the service are not included in the labor market. Thus it is considered that the service still does not provide full social reinsertion. It is clear the positive shift in ways of mental health treatment, and the CAPS becomes synonymous with freedom in its various senses. However, the reinsertion not yet reached spaces other than the CAPS itself.

> Key words: social reintegration; Psychosocial Care Center; Psychiatric Reform; Mental Health. 